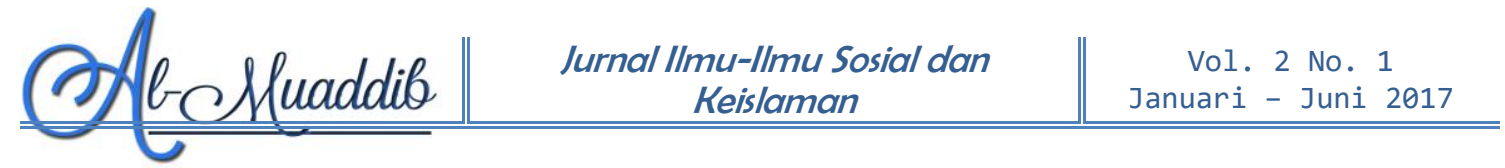

\title{
PENINGKATAN PEMAHAMAN PEMBELAJARAN PAI MATERI SHALAT MELALUI MEDIA GAMBAR KELAS IV SD NEGERI 0713 PIR TRANS SOSA I A TAHUN 2016
}

\author{
Siti Holijah Ritonga \\ SD Negeri 0713 Pir Trans Sosa I A \\ sitiholijahritonga@gmail.com
}

\begin{abstract}
The background in this study is the lack of the use of learning media in a matter of prayer so that the learning achievement is less. The method used in this research is a class act. Collecting data in this study with observation and interview methods. In the data analysis, the authors used data reduction, data display, tentative conclusions and verification. Results of this research is student interest to learn the prayers in public primary schools Pir Trans Sosa 0713 I A after using media images has increased. In the pre-cycle to the first cycle students' interest increased by $92.6 \%$. After using media images of student achievement Elementary School 0713 Trans Sosa Pir I A increased from the first cycle to the second cycle as much as $98.3 \%$. Students who have not yet reached pre-cycle KKM on as many as 13 students and reaching the KKM many as 18 students. In siklusI students who have not reached the KKM as 6 students and has reached the KKM many as 25 students. In the second cycle students who have not achieved as much as 3 KKM KKM students and achieve as much as 29 students.
\end{abstract}

\section{Keywords: Improvement, understanding, prayer materials, media images.}

\section{A. PENDAHULUAN}

Saat ini perlu menelaah kembali praktik-praktik pembelajaran di sekolah-sekolah. Peranan yang harus dimainkan oleh dunia pendidikan dalam mempersiapkan anak didik untuk berprestasi secara utuh dalam kehidupan bermasyarakat saat ini akan sangat berbeda dengan peranan tradisional yang selama ini dipegang oleh sekolah-sekolah. Pendidikan merupakan salah satu sarana untuk meningkatkan kecerdasan dan keterampilan manusia, sehingga kualitas sumber daya manusia sangat tergantung dari kualitas pendidikan tersebut. Melalui 
pendidikan juga dapat dikembangkan kemampuan pribadi, daya pikir dan tingkah laku yang lebih baik.

Kegiatan belajar mengajar merupakan tugas rutin seorang guru dalam mengembangkan bakat dan kemampuan. Untuk itu seorang guru dituntut selalu mengembangkan kecakapan secara profesional dalam mengelola kelas, agar bakat dan kemampuan siswa dapat berkembang secara optimal. Salah satu kecakapan profesional yang perlu dikembangkan adalah kecakapan dalam menggunakan metode pembelajaran yang tepat dan efektif. Kegiatan belajar mengajar di dalam kelas akan efektif apabila seorang guru selalu menggunakan media pembelajaran dalam menanamkan konsep kepada siswa, sehingga dapat menghilangkan konsep verbalitik, khususnya pada pembelajaran yang membutuhkan pemahaman.

Tidak semua sekolah menyediakan sarana dan prasarana yang lengkap untuk mendukung perkembangan dunia pendidikan. Seorang guru yang mengajar di sekolah yang memiliki sarana dan prasarana yang minim harus mampu mengembangkan pembelajaran dengan menggunakan berbagai media, misalnya media gambar. Dengan menggunakan media gambar diharapkan siswa dapat mengetahui pembelajaran yang diajarkan oleh guru tersebut.

Oleh karena itu guru sebaiknya memiliki kemampuan dalam memilih metode dan media pembelajaran yang tepat. Ketidaktepatan dalam memilih metode dan media akan menimbulkan kejenuhan bagi siswa dalam menerima materi yang disampaikan sehingga materi kurang dapat dipahami.

Berdasarkan penjelasan di atas tergambar bahwa diperlukan upaya untuk meningkatkan pemahaman dan aktifitas belajar, khususnya pada mata pelajaran PAI pada siswa SD. Oleh karena itu penelitian ini ingin menemukan alternatif "Peningkatan Pemahaman dan Aktifitas Siswa dalam Pelajaran PAI Mengenai Ibadah Shalat 


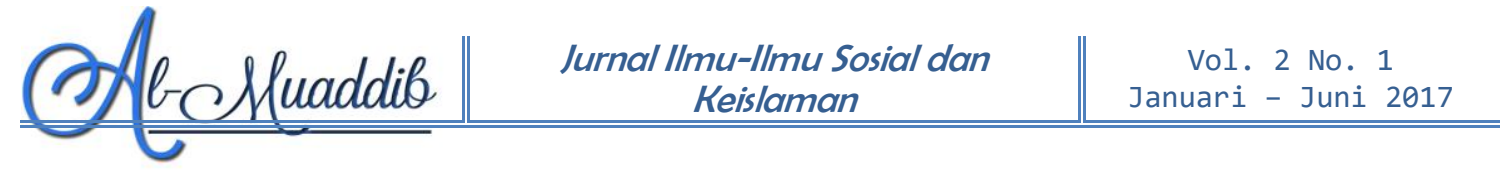

dengan Menggunakan Media Gambar pada Kelas IV SD Negeri 0713 Pir Trans Sosa I A Tahun Pelajaran 2014/2015".

\section{B. METODE PENELITIAN}

Sebelum dilaksanakan pelaksanaan pembelajaran dengan menggunakan media gambar, materi pembelajaran disampaikan oleh guru hanya dengan ceramah saja. Setelah dilakukan proses pembelajaran, guru menganalisa hasil proses pembelajaran dengan menggunakan latihan menjawab soal tertulis. Hasil penilaian berdasarkan nilai KKM untuk Pendidikan Agama Islam yaitu 7,05. Untuk menganalisa prestasi belajar siswa sebelum dilakukan pembelajaran dengan media gambar, penulis menggunakan nilai raport Pendidikan Agama Islam. Penulis juga mengobservasi kondisi saat proses pembelajaran berlangsung. Tahapan dan langlah-langkah yang dilakukan penulis dalam siklus ini adalah :

1. Perencanaan

Dalam tahapan ini tercakup beberapa kegiatan, diantaranya adalah:

a. Refleksi awal

Yaitu penulis melakukan penyimpulan berdasarkan evaluasi terhadap pembelajaran materi shalat yang selama ini dilakukan, yaitu menunjukkan kelemahan kurangnya minat siswa dalam belajar materi shalat. Penyusunan proposal penelitian sesuai dengan pokok bahasan dan instrumen pengumpulan data selama penelitian tindakan ini dilaksanakan. Penyiapan metode untuk mendukung pembalajaran materi shalat dan alat-alat penelitian. Menyiapkan lembar observasi dan lembar tes yang memuat materi pembelajaran shalat. Menyiapkan materi pembelajaran mengenai ibadah shalat dari pengertian, hukum dan bacaan shalat.

b. Pelaksanaan tindakan

Siklus dilakukan pada hari 9 September 2014 dari jam 10.00 sampai jam 11.30. Materi pembelajaran pada siklus I adalah tentang 
pengertian ibadah shalat, hukum shalat dan bacaan shalat. Selama pembelajaran langkah- langkah yang dilakukan sebagai berikut:

1) Menyapa siswa, memberikan salam dan berdoa

2) Mengabsen siswa yang hadir

3) Memberitahukan pengetahuan pembelajaran sebelumnya yang berkaitan dengan materi shalat

4) Menjelaskan tujuan pembelajaran

5) Membagikan gambar tentang tata cara melakukan gerakan shalat.

6) Menjelaskan materi shalat tentang bagaimana melakukan ibadah shalat yang benar dengan menunjukkan gambar tata cara melakukan ibadah shalat

7) Mengamati siswa selama kegiatan pembelajaran dilaksanakan.

8) Melaksanakan post untuk mengetahui sejauh mana kemampuan siswa dalam memahami materi shalat dan sebagai tolak ukur pemahaman siswa tentang materi shalat.

\section{Observasi}

Observasi dilakukan selama pembelajaran dengan media gambar dilakukan. Observasi dilakukan oleh guru kelas. Ada dua pokok yang diobservasi, yaitu evaluasi keaktifan siswa dan kegiatan guru selama pembelajaran. Hasil dari observasi tersebut adalah sebagai berikut;

1) Siswa lebih mudah memahami materi pembelajaran shalat.

2) Siswa lebih mudah melakukan gerakan shalat secara beruntun.

3) Siswa lebih aktif untuk bertanya dengan menunjukkan bagian gambar yang tidak dimengerti.

4) Siswa lebih bersemangat dalam melaksanakan kegiatan belajar mengajar.

5) Terjadi perbedaan persepsi pada siswa perempuan karena gambar yang diberikan adalah seorang laki-laki sedangkan gerakan shalat pada perempuan berbeda.

6) Terjadi saling tanya sesama siswa karena sulit untuk memahami gerakan pada gambar yang mendatail.

\section{Refleksi}

Pelaksanaan siklus I sesuai dengan perencanaan. Dalam obsevasi penulis menemukan beberapa hal yang perlu ditingkatkan, di antaranya:

a. Guru lebih seksama dalam menjelaskan bacaan saat shalat karena setiap gerakan shalat memiliki bacaan sendiri-sendiri.

b. Gambar yang diberikan guru lebih baik yang menarik minat siswa untuk mempelajarinya. 
c. Gerakan shalat yang berukuran kecil, diberikan pembesaran pada beberapa titik agar dapat terlihat jelas.

d. Terdapat perbedaan shalat antara laki-laki dan perempuan, sedangkan yang tersedia adalah gambar laki-laki. Hendaknya guru juga menyiapkan gambar tata cara yang dilakukan oleh seorang perempuan.

\section{HASIL DAN PEMBAHASAN}

Dalam kegiatan belajar mengajar, dituntut adanya penggunaan media yang dapat membantu dalam menyampaikan materi pembelajaran agar mudah dipahami oleh siswa. Penggunaan media yang menarik akan membuat siswa lebih aktif dalam belajar. Apabila penggunaan media yang tidak tepat atau tidak menarik, siswa kesulitan untuk memahami materi pelajaran atau tidak berminat untuk mengikuti kegiatan pembelajara. Siswa yang berminat mengikuti kegiatan belajar mengajar, prestasi yang didapatkan juga akan baik. Untuk mengetahui adanya peningkatan prestasi setelah dilakukan penelitian ini, penulis menyertakan data sebelum dilakukan penelitian.

1. Nilai rata-rata yang diperoleh siswa adalah 78,5 .

2. Nilai KKM yang telah ditentukan adalah 7,5 .

3. Rata-rata tersebut menunjukkan daya serap siswa terhadap materi pembelajaran shalat sebesar 78,5\%

4. Siswa yang belum mampu mencapai nilai KKM adalah 13 siswa sedangkan siswa yang mampu mencapai nilai KKM adalah 17 siswa.

Aktifitas siswa dalam pembelajaran materi shalat. Nilai Aktifitas siswa sebelum dilakukan pelaksanaan siklus didapatkan dari observasi selama kegiatan belajar yang dilakukan sebelum penulis melakukan penelitian. Pemberian skor rentang 1 sampai 4.

\begin{tabular}{|c|l|c|}
\hline No & \multicolumn{1}{|c|}{ Jenis Aktifitas siswa } & Skor \\
\hline 1. & Siswa yang hadir & 31 \\
\hline 2. & Siswa mengikuti pelajaran dengan baik & 23 \\
\hline 3. & Siswa yang dapat menjawab pertanyaan lisan & 4 \\
\hline 4. & Siswa yang bertanya & 6 \\
\hline
\end{tabular}




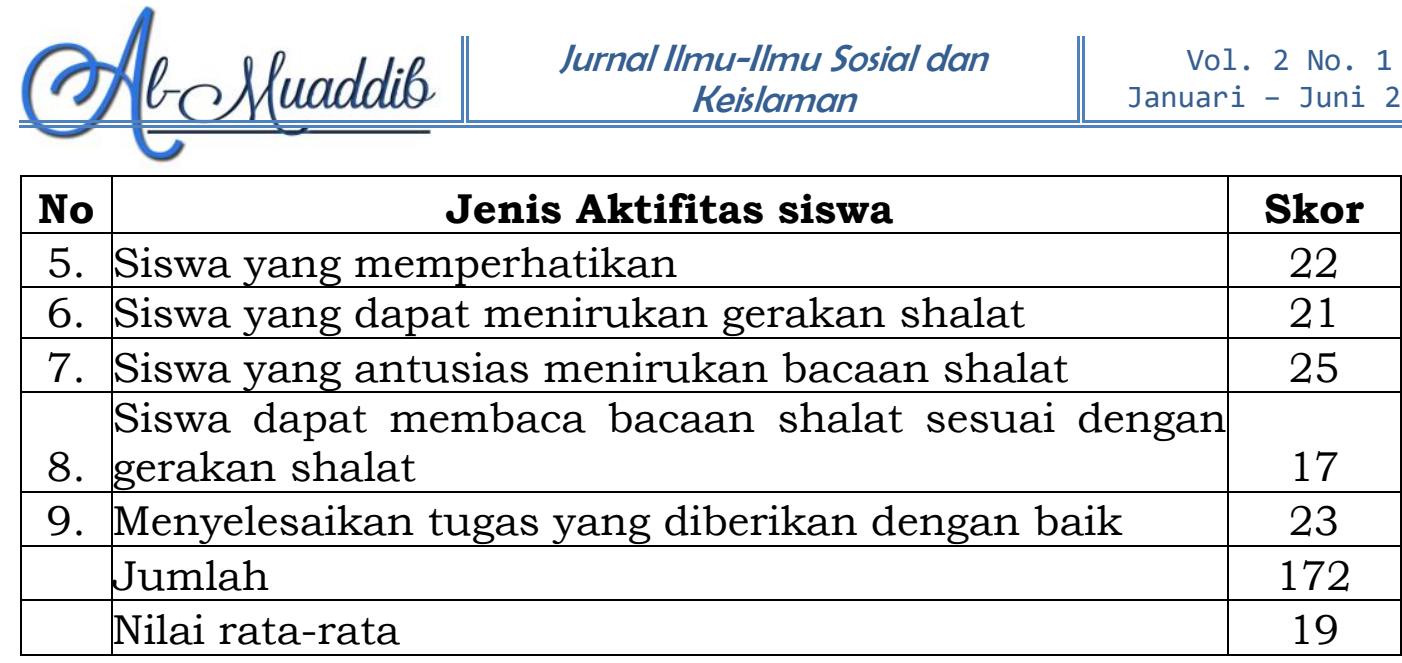

1. Jumlah nilai aktifitas siswa dalam pembelajaran materi shalat adalah 19

2. Jumlah skor maksimal adalah 31 sesuai dengan jumlah siswa.

3. Penilaian terhadap siswa:

a. Aktifitas siswa baik (A) jika skor 24-31

b. Aktifitas siswa cukup (B) jika skor 16-24

c. Aktifitas siswa kurang (C) jika skor 8-16

d. Aktivitas siswa buruk (D) jika skor 0-8

Dari data di atas dapat disimpulkan bahwa nilai aktifitas siswa adalah kurang (B) karena skor dari keaktifan siswa adalah 19. Tingkat aktifitas siswa adalah $19 / 31 \times 100 \%=61 \%$

Dari hasil pelaksanaan siklus I dan siklus II dapat disimpulkan bahwa guru dapat menggunakan media gambar dengan baik dalam pelaksanaan kegiatan mengajar materi shalat. Dari hasil observasi siklus I didapatkan nilai 63,7 dari nilai maksimal 100, sedangkan hasil observasi siklus II didapatkan nilai 84,3. Rata-rata dari kedua siklus adalah 74. Dengan skor ini maka penguasaan guru terhadap materi shalat dengan menggunakan media gambar dikategorikan baik (B).

Dalam pelaksanaan siklus I dan siklus II, siswa menunjukkan aktifitas yang baik meski sering terjadi saling tanya antar siswa tetapi tidak mengganggu kegiatan belajar mengajar yang dilaksanakan. Dari hasil observasi siklus I dan siklus II dapat dilihat di tabel di bawah ini:

\begin{tabular}{|c|c|c|}
\hline No & Jenis keaktifan siswa & $\begin{array}{c}\text { Skor } \\
\text { keaktifan tiap } \\
\text { siklus }\end{array}$ \\
\hline
\end{tabular}




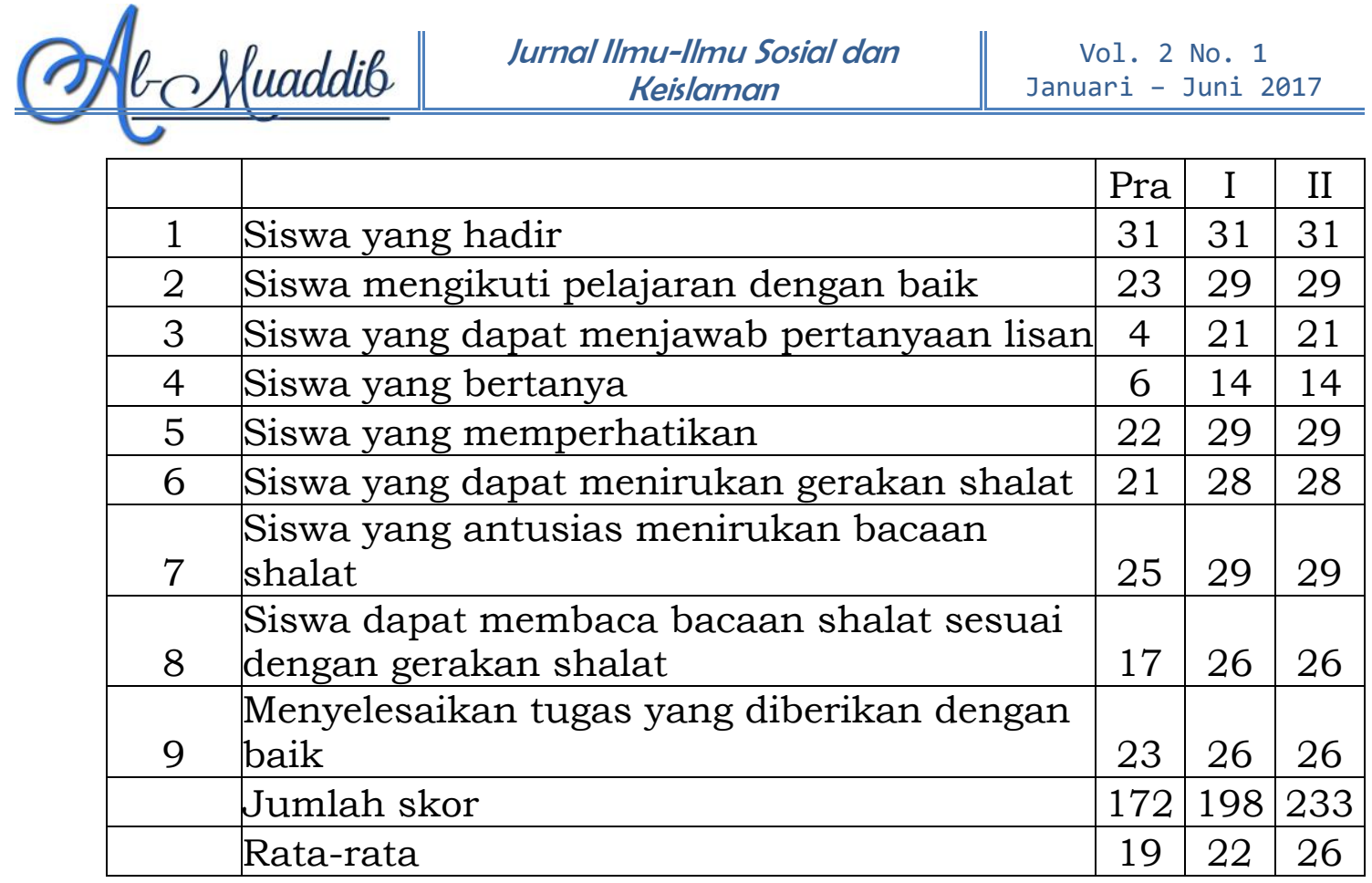

Dari tabel tentang perbandingan aktifitas siswa dalam kegiatan mengajar pada siklus I dan siklus II maka dapat diketahui bahwa :

1. Skor yang didapatkan sebelum pelaksanaan penelitian adalah 19 sedangkan pada siklus I skor yang didapatkan adalah 22 dan siklus II adalah 26. Dengan nilai maksimal skor adalah 31.

2. Setelah dilaksanakan siklus I, terjadi peningkatan skor dari pra siklus dari 19 menjadi 22. Kenaikan skor sebesar 3 siswa atau $13,6 \%$.

3. Siklus II mampu meningkatkan skor dari siklus I dari 22 menjadi 26. Peningkatan skor sebesar 4 siswa atau 12,9\%. Sedangkan peningkatan skor dari pra siklus ke siklus II adalah 15 poin atau $31,8 \%$.

4. Dari data di atas menunjukkan terjadi peningkatan keaktifan siswa dari pelaksanaan siklus I dan siklus II. Jadi dapat disimpulkan bahwa hipotesis pembelajaran dengan menggunakan media gambar dapat meningkatkan aktifitas belajar anak khususnya pada materi shalat pada siswa kelas IV SD Negeri 0713 Pir Trans Sosa I a.

Hasil prestasi belajar siswa setelah pelaksanaan tindakan Untuk mengetahui peningkatan prestasi belajar siswa, penulis menggunakan 


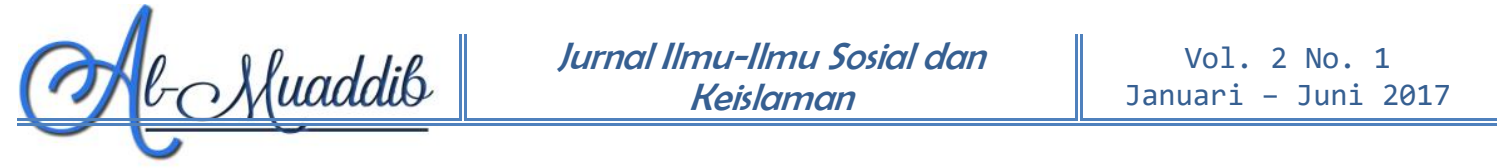

hasil nilai rapor akhir semester sebagai data sebelum dilakukan tindakan. Sedangkan untuk perbandingan setelah dilakukan tindakan, penulis menggunakan pos tes sebagai nilai evaluasinya.

1. Siswa yang belum mencapai nilai KKM pada pra siklus adalah 13 siswa, pada siklus I sebanyak 6 siswa dan pada siklus II sebanyak 3 siswa.

2. Nilai Kriteria Ketuntasan Minimal (KKM) adalah 7,5.

3. Nilai rata-rata pra siklus adalah 75,3 , siklus I adalah 79,8 dan siklus II adalah 82,4.

Meskipun terjadi peningkatan nilai dari pra siklus sampai siklus II, ada beberapa siswa yang belum dapat mencapai nilai KKM sebanyak. Nilai KKM di SD Negeri 0713 Pir Trans Sosa I a adalah 7,5. Hal ini dipengaruhi oleh karena siswa tidak memperhatikan penjelasan guru, penjelasan guru yang terlalu cepat dan media gambar yang gambarnya kurang mendetail.

Dari data di atas dapat disimpulkan bahwa pernyataan hipotesis pembelajaran dengan menggunakan media gambar dapat meningkatkan pemahaman dan aktifitas belajar anak khususnya pada materi shalat pada siswa kelas IV SD Negeri 0713 Pir Trans Sosa I a.

\section{SIMPULAN}

Dari analisa data yang telah penulis lakukan, maka dapat dibuat kesimpulan:

1. Kegiatan pembelajaran dengan menggunakan media gambar dapat meningkatan minat dalam pelajaran PAI mengenai ibadah shalat dengan bukti terjadi peningkatan nilai dari pra siklus ke siklus I yaitu dari 75,3 menjadi 79,8. Siswa yang belum mencapai nilai KKM pada pra siklus sebanyak 13 siswa sedangkan pada siklus I sebanyak 6 siswa.

2. Dengan menggunakan media gambar, prestasi siswa dapat meningkat. Hal ini dapat diketahui dari peningkatan nilai rata- 
rata siklus I menjadi siklus II. Nilai rata-rata pada siklus I adalah 79,8 sedangkan pada siklus II 82,4. Dan untuk siswa yang belum mencapai nilai KKM pada siklus I sebanyak 6 siswa sedangkan pada siklus II sebanyak 3 siswa.

\section{E. SARAN}

Dari penelitian yang telah dilakukan oleh penulis, maka perlu dikemukakan beberapa saran sebagai sumbangan pemikiran bagi beberapa pihak yang terkait dalam pelaksanaan penilitian ini semoga dapat menjadi bahan pertimbangan untuk memperbaiki dan meningkatkan kualitas pendidikan. Adapun saran yang disampaikan penulis adalah:

1. Untuk pihak sekolah akan lebih baik jika media gambar yang disediakan untuk proses pembelajaran dilengkapi dan dibuat lebih menarik agar para siswa lebih berminat dalam belajar.

2. Untuk guru akan lebih baik jika guru lebih menguasai dalam penggunaan media gambar sehingga penyampaian materi dapat sesuai dengan media gambar.

3. Untuk kepala sekolah, lembaga pengelola pendidikan diharapkan dapat meningkatkan selaku Pembina dalam meningkatkan pengetahuan dan ketrampilan para guru dilingkungan binaannya sehingga terwujud guru professional yang sanggup meningkatkan mutu pendidikan.

4. Penelitian ini dirasakan masih banyak keterbatasannya, oleh karena itu diharapkan adanya tindak lanjut dan penyempurnaan dari peneliti berikutnya. 
DAFTAR PUSTAKA

Bachrul Ilmi dkk, Pendidikan Agama Islam untuk SMK Kelas XI, Bandung: Gravindo Media Pratam, 2007.

Hariyoto dkk, Pendidikan Agama Islam 3, Yogyakarta: Muria Baru, 2008.

Kavie, Pengertian Pendidikan, http://kaviedesign.indinesiaforum.net/t8-pengertian-pendidikan

Masykuri Abdurrahman, Kupas Tuntas Salat Tata Cara dan Hikmahnya, Jakarta: Erlangga, 2006.

Silabus Pendidikan Agama Islam Semester 1 dan 2 SDN Sukorejo I Mertoyudan Magelang Tahun 2010/2011

Sudarwan Danim, Media Komunikasi Pendidikan, Jakarta: Bumi Aksara, 1995.

Sunaryo, Psikologi untuk Keperawatan, Jakarta: EGC, 2004.

Tafsir, Ahmad. Metodologi Pengajaran Agama Islam, Bandung: Remaja Rosdakarya, 1995.

Tim Pengembangan Ilmu Pendidikan FIP-UPI, Ilmu dan Aplikasi Pendidikan, Jakarta: PT Imperial Bhakti Utama, 2007.

Tim Penyusun Kamus Pusat Bahasa, Kamus Besar Bahasa Indonesia, edisi ketiga, Jakarta: Balai Pustaka, 2001.

Tim penyusun kamus pusat bahasa, Kamus Besar Bahasa Indonesia, Jakarta: Balai Pustaka, 2001.

Tim Peyusun, Pendidikan Islam dan Tantangan Globalisasi Buah Pikiran Seputar Filsafat Politik Ekonomi Sosial dan Budaya, Yogyakarta: PRESMA Fakultas Tarbiyah UIN Sunan Kalijaga Yogyakarta, 2004.

Wahyudin dkk, Pendidikan Agama Islam untuk Perguruan Tinggi, Jakarta: Grasindo, 2009. 